\title{
Socio-Scientific Issues, Sustainability and Science Education
}

\author{
Russell Tytler
}

Published online: 29 October 2011

(C) Springer Science+Business Media B.V. 2011

The papers in this special issue provide a variety of perspectives on SSI and sustainability linked to science education. Indeed, if one were looking for some indication of convergence in this growing area of research interest one would not find a clear indication of it here. However, the papers are interesting for this very reason of their diversity, since they represent a number of strands of thinking relating sustainability and SSIs, and school science. While the papers all relate centrally to SSI as an approach to teaching and learning, they focus to a varying degree on sustainability, and on science. In this commentary, I will first attempt an overview of the issues they raise and attempt to situate them with respect to some common strands of thinking, before responding to the key implications I see in the papers for the school science curriculum. I will justify doing this on three grounds. First, all the papers in some measure have things to say about pedagogy, structure and epistemology of school science, and they say this in interestingly different ways. Second, whatever the historical approach in environmental education/ESD research, often involving an antagonistic stance to the traditional science curriculum and its companion epistemology (an issue raised by Robottom and echoed to some degree in a number of the other papers), these papers as a set demonstrate clearly the important role that the school science curriculum could, and sometimes does, play in student learning about sustainability. In fact, on my reading, the 'pointy end' of the issues raised in the papers relates to this issue of the nature and status of science knowledge in the curriculum and its appropriate role. Third, I have a longstanding interest in reform in science education, and the issues raised in these papers provide some powerful commentaries on the ways that science education might be, and should be framed if it is to engage students in a science that is relevant and powerful for them as future citizens.

The papers have much to say on a number of important curriculum dimensions:

1. the structures of teaching and learning about SSI related to the science curriculum area

2. the pedagogies evident in the models of SSI teaching and learning

3. the broader purposes that frame the interventions

4. the epistemological stances evident in the interventions described, particularly concerning the status and setting of scientific knowledge

R. Tytler $(\bowtie)$

Deakin University, Geelong, Australia

e-mail: tytler@deakin.edu.au 
On all these matters, the papers diverge considerably. For some papers, particularly those of Jean Simonneaux and Laurence Simonneaux and to some extent Lange, these distinctions are made within the paper and a range of interventions are described that represent variation across the dimensions.

\section{The Curriculum Framing of SSI and Sustainability Interventions}

While these papers describe interventions that cover a spectrum of arrangements for SSI and sustainability teaching and learning, fundamentally they describe two ways in which the intervention relates structurally to the normal school discipline-based curriculum - those interventions that sit squarely within a science curriculum framing, and those that involve a much more contextual approach for which science knowledge purposes are not the prime goal. For these, the context drives the logic of the study, and is often local, and multi-disciplinary.

In the first category the interventions are essentially framed within a science curriculum organized around traditional knowledge based topics. In each case however the interventions are interesting for the way that they broaden the purposes of school science, even as they sit within more traditional structures. Thus, in the Tomas and Ritchie study, imaginative essays on biosecurity issues sit within a biosecurity unit, with the SSI framed to broaden the scope of traditional science purposes to include knowledge of the societal interactions of science, broadening the genres of science writing students are exposed to, and engaging them through this expression of public participation in an SSI. The BravoTorija/Jimenez-Aleixandre paper describes an intervention where students pursue particular sustainability goals as a natural extension to ecology studies, within the limitations of a crowded curriculum. This is essentially a one-lesson intervention that both introduces a richer vein of (science) thinking about energy flow within a food web, and introduces the sustainability concept in terms of fishery management that can provide food over the long term. Like the Tomas and Ritchie study, the issue is not locally contextual, and the goals are correspondingly constrained. In this approach, non-local contexts are framed by the teacher or by literature research. The Spanish case is situated within a science curriculum that includes standards related to sustainability. I will discuss later and in more detail this question of the framing of sustainability and SSIs. The Klosterman et al. paper does not describe an intervention as such but takes as its starting point the possibility of teachers, within the science curriculum, using media to introduce SSIs. Here, the purpose is to pursue a scientific literacy notion of critical media reading. While the bar seems to be set reasonably low in this analysis for what would count as a legitimate SSI undertaken by teachers, the study shows that teachers, without support, will tend not to stray outside their traditional disciplinary boundaries even to a minor extent. The paper thus underlines the challenges for introducing SSI and sustainability into a traditional curriculum even in committed schools.

The first paper in the second category is that by Bencze et al., which looks at the possibility of introducing substantial SSI-sustainability studies within the science curriculum, as part of a project with committed teachers. The study is explicitly aimed at nurturing activist commitments, beyond aims relating to science conceptual and procedural knowledge. In this study the students carry out science-based investigations around issues they decide on, and develop to varying degrees activist commitments relating to sustainability. Here, as with the Klosterman et al. paper, the difficulty of instituting change within a traditional science curriculum is clearly demonstrated. The paper sits in some sense 
between the categories in that the issues that students follow are local and contextual and are pursued for their worth, with science taking a supporting role as it does in authentic settings. Nevertheless the interventions proceed within the formal curriculum, and for some teachers it leads to more radical activist outcomes than for others.

Ian Robottom describes a large scale Asian investigative project initiative which lies outside normal curriculum frameworks and which, in the examples he describes, the student investigations are intensely local, multi-disciplinary, and socially progressive in the sense of being concerned to develop science in the interests of social well being. He speculates upon the possibility of this work being contained within normal curriculum frameworks and concludes that such work is inevitably contextually idiosyncratic. This work is different in kind from the projects described by Bencze et al. in that their aim is to respond to and plan for intervention to meet a local sustainability need - a techno-scientific intervention-rather than developing a personal plan of action and a social intervention. I would see these as being of a kind with a community-linked project described by Rennie (2006) in which students in a logging town identified the cause of smog as due to home heating technologies and acted with the council to devise policies to reduce this. The three projects described by Jean Simonneaux and Laurence Simonneaux all fall outside the scope of the 'normal' science curriculum in taking context seriously, and offering a critical perspective on the contribution of science to resolving ESD issues. This criticality ranges from acknowledging the limitations of science in resolving competing positions, to raising questions about the status of scientific knowledge itself. The Lange paper similarly describes projects that, while incorporating knowledge that sits within traditional curriculum boundaries, leads towards contextually specific and multidisciplinary interventions. We thus have, within these papers, a spectrum of possibilities for relating SSIs to science within the school curriculum.

\section{Pedagogies Underpinning the Interventions}

One thing most of the interventions had in common was an inquiry where students responded to problems in ways they had a good deal of control over, and were supported to develop both conceptual and dispositional resources. The problems they responded to were in varying degrees local or universal, with different degrees of scaffolding built into the tasks. In some of the tasks they were supported with sophisticated and complex information developed with considerable resource input, such as in the Simonneaux case study of companion modeling around a biodiversity issue regarding pine plantations. In others they were individually autonomous in developing strategies and solutions such as in the SEAMEO projects described by Robottom. In some cases students worked individually, and in other cases team and even community collaboration and action was central to the task.

\section{The Purposes That Frame the Intervention}

A range of purposes for the pursuit of SSIs can be discerned across the papers, with varying degrees of emphasis. One purpose most of the papers have in common is the awareness of the pressing nature of sustainability issues and the way that science and technology knowledge contributes to an understanding of these or otherwise interacts with the issue. This knowledge of STSE interactions takes different forms, however, 
seeing science and technological knowledge and products on a scale from benign to harmful. Thus, Bravo-Torija and Jimenez-Aleixandre describe students learning how knowledge of energy relations in a food web can help design sustainable fishery policy, and show how both science and sustainability knowledge interact to achieve a high level solution; Jean Simonneaux and Laurence Simonneaux provide examples of the sophisticated use of modeling of plant and animal reproduction and interactions to explore a biodiversity management issue within a 'companion modeling' framework, and separately take a critical stance on the nature of the scientific knowledge used to analyse food production or packaging policy; Lange describes science and mathematics teaching to support deeper understandings of climate change, and multi-disciplinary approaches to consideration of the effects of weather on human populations; in the Bencze paper (although this was not a feature they emphasized in the analysis) scientific tests were used to establish that bottled water has no superior qualities to tap water. In the interventions therefore, knowledge of representations of scientific concepts was important in resolving the issue, but there was a strong emphasis on the contextual relevance of this knowledge in not only understanding the sustainability agenda but in acting to effect this. The stance on science knowledge also differed. I will discuss this epistemological dimension separately.

Beyond STSE/sustainability knowledge, the purposes of SSI interventions found in these papers include increased engagement with science, a focus of the Tomas/Ritchie paper; greater critical awareness of media (Klosterman et al.) or appreciation of different genres one can use to communicate science (Tomas/Ritchie); and knowledge of investigative processes that are wider than the traditional 'variable control' design (Bencze et al.). An important outcome for a number of the projects was a disposition to act in the interests of sustainability or on other aspects of STSE interactions. Thus, we find a commitment to maintaining cultural identity and teasing out interactions between environmental, social and economic interests (Robottom); and a commitment to an activist stance was central to the STEPWISE project (Bencze et al.). These purposes echo the knowledge-attitude-action framework (Ballantyne and Packer 2005) used in environmental education. Lange, and Simonneaux, unpack this notion of dispositions in interesting ways. Lange invokes the notion of 'otherness' to describe two distinct stances on the perception of actual or impending catastrophe; one essentially a pessimistic and helpless response premised on the idea that others are to blame, and the other a galvanizing stance involving the need for communal and personal action. I see this as linked to the self efficacy discussion in the Bencze et al. paper. The Simonneaux paper takes critical reflexivity as a fundamental outcome of SSIs, and argue for student active participation in scientific/social processes as a key pedagogical approach as well as a fundamental scientific literacy outcome. This issue of dispositions is a critical one for framing a stance on the place of SSIs in a curriculum designed for citizen action, and for developing an adequate curriculum response to a radical notion of scientific literacy.

\section{Epistemological Stance}

One of the key critiques of science education concerning its capacity to support a sustainable development agenda is the positivist epistemological underpinning of traditional science curricula and pedagogies, which makes it difficult to properly discuss the complex and contingent nature of science knowledge as it applies to SSIs. Ian Robottom alludes to this in describing a participatory action research methodology as needed to explore sustainability SSIs. The Lange and Simonneaux papers discuss this issue in detail, with Jean Simonneaux and Laurence Simonneaux identifying a number of distinct epistemological stances and 
corresponding conceptions of science knowledge that drive different approaches to SSI. Their model could be used to position the other interventions. Bravo-Torija/Jimenez-Aleixandre are critical of the epistemology represented in traditional science pedagogy. The intervention they describe, however, involves the application of canonical science concepts to sustainability planning, and would be consistent with the 'utilitarian' stance of the Simonneaux analysis, and a 'pragmatic didactic strategy'. Similarly, Bencze criticizes the way the positivist epistemology of traditional curricula and their uncritical 'infomercial' stance to science. Yet the student projects they describe seem to involve multiple epistemological and methodological positions. For instance, science is used productively to critique common assumptions about water quality. In these interventions, the role of science in supporting or constraining understandings and action in these SSIs is complex.

In science studies, the ground is shifting with regard to the epistemological underpinnings of science practice, and there have been calls within science education itself for classroom practices to better represent the complex, contextual and contingent nature of the epistemic practices of science (Duschl and Grandy 2008). This issue of the alignment of current views about the nature of science with a productive approach to education for sustainability, is worth revisiting.

\section{Repositioning Science Education to Accommodate SSI Perspectives}

Dealing with sustainable development issues involves acknowledging competing value positions and interests. The legitimacy of wider viewpoints than scientific and technological knowledge and perspectives in resolving or even understanding these complex problems is universally recognized. The proper accounting of context is a major theme in contemporary science education research (Pilot and Bulte 2006) and has been well recognized in major curriculum projects. In the past I have been involved in writing curricula with context as the core organizing principle, and experienced the contestation with science academy interests that this entailed (Hart 2001). However, in more recent times there has been wide acknowledgment within the scientific community of the need to have a more sophisticated representation of science practices within school science, and the need to better engage students in contemporary settings of science. Thus, in a set of recent focus group interviews with practicing science professionals, these scientists working in areas of climate change, health, water, infectious disease containment and modern materials were very cognizant of the public aspects of their work in terms of knowledge and support, and value positions, and correspondingly critical of the impoverished version of science represented in their own children's curricula (Tytler and Symington 2006; Tytler 2007). Academies of Science have for many years advocated a more radical inquiry approach to teaching science than schools and teachers seem to be able to envisage. Correspondingly, while there have been significant contestations of the epistemological positions of science in the so called 'science wars', more temperate accounts (Osborne et al. 2003) have shown considerable agreement between scientists, sociologists and educators on the nature of scientific epistemic processes and the status of scientific claims. Modelling processes are increasingly recognized as central to science. Researchers in science studies (Duschl and Grandy 2008; Latour 1999; Nersessian 2008) have identified the complex, contextual, contingent and cultural representational practices used to establish and validate science knowledge. While this research has shaken belief in the notion that science knowledge can make claims to absolute truths, there seems to be general acceptance that the epistemic approaches of science represent the 'best game in town'. 
The importance of science methods and knowledge is acknowledged in the papers in this special issue, and the contribution of science to these complex issues forms an essential component of the interventions described. Critique of epistemological positions taken by science in these complex and contemporary SSIs seems to relate to a) the simplistic positivist position underpinning transmissive curriculum traditions, and 2) the fact that contemporary science knowledge generated in these SSI situations of uncertainty and complexity are often taken to be more authoritative than is justifiable. Yet to overstate this contingent nature of science findings, and to fail to have students understand something of the nature of knowledge building processes of science, carries huge risk.

Recently, there has been considerable concern with levels of student engagement with science, and scientific literacy has been advocated as the chief purpose of science education. The papers in this special issue represent a variety of approaches that could provide ways forward for developing a serious engagement with a science literacy agenda, and the possibility of increased engagement of students with a richer version of science knowledge and practice. However, these papers offer quite various models of the place of SSIs, and sustainability, within a mainstream science curriculum, with different degrees of emphasis on science knowledge and wider outcomes. There is no doubt that a shift to SSI education as the basis of mainstream science education would significantly trouble gatekeepers in the science education community. While I was reviewing these papers, for instance, I came across a front page article in the UK Guardian newspaper describing an authoritative call for abandonment of an 'issues based' science education and a return to the teaching of basic science principles, on the basis that these are timeless in their applicability. Quite apart from these political barriers to SSI education, there is the substantive issue of a need to develop a capacity in students to work with key scientific concepts and methods at increasing levels of sophistication. The question becomes, how might these papers be used to provide models of how science education might be re-imagined to pursue a wider and more radical literacy agenda including sustainability concepts and dispositions. I will conclude this reflection by considering this from two perspectives. The first concerns pedagogies that represent more sophisticated epistemological stances to knowledge and practices in science. The second concerns ways that science curricula need to be structured to support the range of outcomes represented in these papers.

\section{A Representation Construction Pedagogy}

A major dilemma in science education concerns how to bridge the contradiction inherent in developing, on the one hand, students' knowledge of science as a set of ways of understanding the world - the product of centuries of thinking about how best to conceptualise phenomena, and on the other hand their perceptions of science and science knowledge as continually contested and revised (Osborne 2006) - to introduce them to the epistemic processes of science, and its human aspects. The papers in this special issue would mostly emphasise this latter view, but in some, for instance the Bravo-Torija/Jimenez-Aleixandre, Klosterman et al., or Tomas/Ritchie papers, the consideration of this contestation sits within an otherwise traditional approach to science teaching and learning. It would be important, in my view, to extend this view of the constructed and contestable nature of science knowledge to the teaching and learning of science generally, even in the Simonneauxs' 'universal' sense. This would imply a broadly constructivist, inquiry approach to teaching (as Robottom argues) but even here the knowledge 'end product' is usually conceptualized as resolved and true in an absolute sense. The representation construction approach we have been working on recently (Tytler and Prain 2010; Hubber et al. 2010) focuses on science knowledge as a set of specific 
literacies rather than universally resolved accounts of 'how things are'. In this pedagogy students are challenged to represent phenomena in varied ways and are led, through negotiation, to the canonical forms of science as representations, or models, that align with experience and explain in powerful ways. The epistemology is explicitly pragmatist, drawing heavily on Peirce (1931). Thus, even with established science such as moon phases or the particulate nature of matter, the epistemological stance is utilitarian and skeptical in the sense of the Simonneaux paper, and the knowledge conceived of as engaged and contextualized. In further work on this pedagogy we plan to extend to SSI approaches, and I would argue that the knowledge stance adopted sits naturally with the flexible conceptions needed for students to grapple with complex and contested, contemporary sustainability issues.

\section{Structuring the Science Curriculum}

If we are to seriously engage the school science curriculum with an SSI approach to teaching and learning sustainability, then this would need to be formally written into curriculum structures and documents. As the Klosterman et al. paper clearly and disappointingly shows, teachers will maintain traditional modes unless there is pressure to change. The Bencze et al. paper also demonstrates the importance of teacher epistemology and school commitments in supporting an SSI curriculum approach, as well as a curriculum structure within which such work can sit. The Bravo-Torija/Jimenez-Aleixandre paper provides one curriculum structure model, where lists of standards include sustainability statements, in this case 'to deduce practical consequences in sustainable management of some resources' added to a standard on trophic levels. This approach is used in other curricula, for instance the current South Australian curriculum contains such standards statements. The approach has the advantage of providing a specific requirement for addressing sustainability and also explicit advice on how to go about this. From a knowledge perspective such as is promoted in the paper, it works well.

However, the building in standards in this way can constrain and limit sustainability teaching. The approach would not cover the innovations described in Bencze et al.'s STEPWISE project. In particular it may not encourage innovations involving local and multi-disciplinary actions such as those described by Lange, or Simonneaux, and it does not address the attitudinal objectives and commitments to action emphasised in these papers. In the new Australian curriculum, there is a strand 'Science as a Human Endeavour' that sits alongside conceptual knowledge, and knowledge of inquiry processes, that introduce the possibility of opening up science curriculum objectives to include considerations of the nature of science and its interactions with society. The exploration of student knowledge development in the Bravo-Torija/Jimenez-Aleixandre paper for instance provides a model for exploration of the nature of sustainability knowledge that could serve as the basis for describing outcomes under such a strand. Jean Simonneaux and Laurence Simonneaux point to conceptions of science knowledge (plural, engaged, contextualized) that could also be used as a basis for thinking about increasing student sophistication in grappling with science knowledge in SSI contexts.

This still leaves the question of disposition, which is central to many of the papers in this issue. Tomas and Ritchie focus on student affect, and use a standardized measure supported by qualitative analysis to establish a range of emotional responses to the science. The study shows clearly the importance of social relationships as the site of positive attitudes with students, since most of the positive responses seem allied to interactions with the teacher or other students, and also the positive repercussions of allowing students to frame their response to scientific issues in their own way. In my view, there are many links in this paper 
to the notion of student identity construction around scientific perspectives. Identity is also an issue for Robottom, and Bencze et al. The treatment of dispositions is different in the Bencze et al. paper, with a focus on active engagement with and a commitment to action on sustainability issues. The six criteria that relate to students' commitment to activism provide a useful set of dispositional dimensions that could help frame curriculum outcomes. Lange talks of moving students to consideration of 'otherness' in terms of the possibility of human action to reduce vulnerability, as a requirement for progression to action. His tripartite method starts with scientific models and conceptions and moves through prospective scenarios to collective actions. For Jean Simonneaux and Laurence Simonneaux, the aim of SSI education is to 'encourage participation and action in the scientific activity' rather than simply to learn to understand. For Robottom, praxis is a fundamental organizing principle, involving students in active, relational practice.

Insofar as SSI education implies utilizing scientific and other knowledge to commit to action, student dispositions are central to curriculum outcomes. I would argue that if we are to promote SSI education linked with the science curriculum, then within standards or outcomes relating to human interactions with science there needs to be a strong commitment to dispositional outcomes. These papers provide some interesting models for what we might mean by student disposition to utilize science and other ideas to meaningfully act. Further research is needed to expand our understanding of how we might more sharply describe dispositional outcomes in respect to sustainability issues in science education curriculum.

\section{References}

Ballantyne, R., \& Packer, J. (2005). Promoting environmentally sustainable attitudes and behaviour through free-choice learning experiences: what is the state of the game? Environmental Education Research, 11 (3), 281-295.

Duschl, R., \& Grandy, R. (Eds.). (2008). Teaching scientific inquiry: Recommendations for research and implementation. Rotterdam: Sense Publishers.

Hart, C. (2001). Examining relations of power in a process of curriculum change: The case of VCE physics. Research in Science Education, 31, 525-551.

Hubber, P., Tytler, R., \& Haslam, F. (2010). Teaching and learning about force with a representational focus: Pedagogy and teacher change. Research in Science Education, 40(1), 5-28.

Latour, B. (1999). Pandora's hope: essays on the reality of science studies. Cambridge: Harvard University Press.

Nersessian, N. (2008). Model-based reasoning in scientific practice. In R. Duschl \& R. Grandy (Eds.), Teaching scientific inquiry: Recommendations for research and implementation (pp. 57-79). Rotterdam: Sense Publishers.

Osborne, J. (2006). Towards a science education for all: The role of ideas, evidence and argument. Proceedings of the ACER Research Conference: Boosting Science Learning -What will it take? (pp. 25). Accessed March 2010 at http://www.acer.edu.au/research conferences/2006.html

Osborne, J. F., Ratcliffe, M., Collins, S., Millar, R., \& Duschl, R. (2003). What 'ideas-about- science' should be taught in school science? A Delphi Study of the 'Expert' Community. Journal of Research in Science Teaching, 40(7), 692-720.

Peirce, C. S. (1931-58). Collected Papers of Charles Sanders Peirce. 8 Volumes (Eds. Charles Hartshorne, Paul Weiss \& Arthur W Burks, Vols 1-6), (Ed., Arthur W. Burks, vols 7-8). Cambridge, MA: Harvard University Press.

Pilot, A., \& Bulte, A. (2006). Why do you 'need to know'? Context based education. International Journal of Science Education, 28(9), 953-956.

Rennie, L. (2006). The community's contribution to science learning: Making it count. Proceedings of the ACER Research Conference: Boosting Science Learning-what will it take? (pp. 6-11). Melbourne: Australian Council for Educational Research. Accessed March 2010 at http://www.acer.edu.au/ research_conferences/2006.html 
Tytler, R (2007). Re-imagining Science Education: Engaging students in science for Australia's future. Australian Education Review No. 51. Australian Council for Education Research, ACER press. www. acer.edu.au/research reports/AER.html

Tytler, R., \& Prain, V. (2010). A framework for re-thinking learning in science from recent cognitive science perspectives. International Journal of Science Education, 32(15), 2055-2078.

Tytler, R., \& Symington, D. (2006). Science in School and Society. Teaching Science, the Journal of the Australian Science Teachers Association, 52(3), 10-15. 